\title{
Hybridization and geographic distribution shapes the spatial genetic structure of two co-occurring orchid species
}

\author{
Patrícia Sanae Sujii ${ }^{1}$ Salvatore Cozzolino ${ }^{2} \cdot$ Fábio Pinheiro $\mathbb{0}^{3}$
}

Received: 17 May 2019 / Revised: 11 July 2019 / Accepted: 17 July 2019 / Published online: 7 August 2019

(c) The Author(s), under exclusive licence to The Genetics Society 2019

\begin{abstract}
Multiple ecological and life-history traits shape the fine-scale spatial genetic structure (FSGS) of a given population. The occurrence in core versus peripheral populations, levels of outcrossing, pollen and seed dispersal, and hybridization are important biological properties that influence the kinship of individuals within populations. We examined spatial genetic structure within 15 populations of Epidendrum fulgens and E. puniceoluteum distributed along a linear gradient of Brazilian coastal vegetation, including both allopatric and sympatric populations where the two orchid species hybridize. We analyzed 581 mapped specimens using nine simple sequence repeat loci, aiming to investigate how geographic distribution and hybridization shape within-population FSGS. A significant increase in FSGS was found towards peripheral populations, compared to core populations. Analysis of short-distance and long-distance components of FSGS identified biparental inbreeding and higher levels of FSGS at peripheral populations, when compared to core populations. In contrast, the relatively high density of reproductive adults in core populations potentially leads to highly overlapping seed and pollen movement, decreasing FSGS. Hybridization was an important factor shaping within-population spatial genetic structure at sympatric sites, decreasing the FSGS observed in parental species. Our results indicate that different ecological forces act in concert to create a gradient of FSGS along species distribution ranges, shaped by extensive levels of intraspecific and interspecific gene exchange.
\end{abstract}

\section{Introduction}

In natural plant populations, fine-scale spatial genetic structure (FSGS) is shaped by multiple ecological and lifehistory traits that influence the patterns of seed and pollen dispersal (reviewed in Vekemans and Hardy 2004). Higher levels of FSGS have been reported for selfing and clonal species, and in low-density populations (Vekemans and

Supplementary information The online version of this article (https:// doi.org/10.1038/s41437-019-0254-7) contains supplementary material, which is available to authorized users.

Fábio Pinheiro

biopinheiro@yahoo.com.br

1 UDF Centro Universitário, Brasília, Brazil

2 Department of Biology, Complesso Universitario di Monte S. Angelo, Università degli Studi di Napoli Federico II, 80126 Napoli, Italy

3 Departamento de Biologia Vegetal, Universidade Estadual de Campinas, Instituto de Biologia, Campinas, Brazil
Hardy 2004; Volis et al. 2010; Binks et al. 2015). However, typical life-history traits related to dispersal mechanisms, such as pollen and seeds dispersed by wind or animals (Petit et al. 2005), can show low power to predict the magnitude of FSGS (Vekemans and Hardy 2004), suggesting that additional biotic and abiotic interactions within populations may act in concert restricting gene exchange over small spatial scales. For instance, different life-history stages, such as seedlings versus adult plants, may increase (Jacquemyn et al. 2006) or decrease (Berens et al. 2014) FSGS due to the interaction of local selection and the historical context of populations. Variation in local kinship patterns was also found among successive stages of population succession, comprising expansion, maturation, and senescence (Chung et al. 2007). When multiple populations are sampled, different ecological and evolutionary processes are revealed, clarifying why patterns of FSGS change along species distribution ranges. Variation in mating systems (Barbará et al. 2008; Meeus et al. 2013) and different edaphic and climatic conditions (Kay et al. 2018; Mosca et al. 2018) may translate into substantial differences in FSGS. 
One way to investigate the origin of contrasting FSGS consists of comparing patterns among populations occurring in different ecological contexts, such as comparisons between core and peripheral populations. Several empirical studies have shown that genetic diversity decreases towards species range limits (Eckert et al. 2008; Guo 2012), due to a decrease in gene exchange and increased levels of drift. Lower population densities and increased levels of inbreeding are also expected in marginal populations, when compared to core populations. Consequently, the population structure of geographic range margins is a key issue for understanding how range limits are established due to the occurrence of potential local adaptation and demographic changes (Sagarin and Gaines 2002; Eckert et al. 2008). Species showing linear distributions over larger latitudinal gradients provide excellent opportunities to compare core versus marginal populations, because range limits are imposed by different ecological factors in opposite margins of the geographical distribution. Indeed, species distributed along coastal vegetation communities have revealed contrasting demographic and genetic patterns at their southern and northern range limits (Herlihy and Eckert 2005; Darling et al. 2008; Samis and Eckert 2009; Pinheiro et al. 2011; Meireles and Manos 2018). Moreover, FSGS studies have detected demographic changes at core, northern, and southern ranges of species distributed along linear latitudinal gradients (Gapare et al. 2005; Pandey and Rajora 2012; Torroba-Balmori et al. 2017).

Patterns of genetic diversity and demography may change due to the presence of hybrid zones along species distribution ranges (Cannon and Lerdau 2015). Species ranges can be limited by hybrid zones because interspecific gene exchange may produce negative gene interactions, decreasing fitness and densities of parental species and hybrids at contact sites (Bridle and Wines 2007). Conversely, hybridization may facilitate species range expansion, including the colonization of new habitats (Lewontin and Birch 1966; Pfennig et al. 2016). The introgression of adaptive alleles may increase the adaptive potential of parental species, which can expand their geographic range, increasing genetic diversity and effective population sizes, and decreasing extinction risks (Cannon and Lerdau 2015; Pfennig et al. 2016). In this situation, hybrids act as bridges for gene exchange between parental species, and overall levels of FSGS within sympatric populations, including parental species and hybrids, are expected. When parental taxa occur in sympatry but in segregated habitats, introgression will expand the spatial limits of heterospecific alleles in the recipient species, decreasing the FSGS observed in hybrid zones (Valbuena-Carabaña et al. 2007). Unfortunately, few studies have attempted to study hybrid zones using an FSGS approach (Cornman et al. 2004; Van Loo et al. 2008; Field et al. 2011).
To test the hypothesis that geographical location influences the genetic relatedness of individuals within the population, we compared the extent of FSGS in core and peripheral populations of the abundant and widespread terrestrial orchid Epidendrum fulgens. Previous research has shown a significant decrease in genetic diversity and the occurrence of bottlenecks at marginal populations of $E$. fulgens (Pinheiro et al. 2011). In the central portion of its distribution, E. fulgens co-occurs with E. puniceoluteum, where hybridization and introgression has been reported (Pinheiro et al. 2010; Moraes et al. 2013). At sympatric sites, each parental species occurs in different but adjacent vegetation types. Hybrids do not exhibit such ecological preferences and are found growing together with both parental species (Pinheiro et al. 2010). These findings suggest that hybrids may change the overall levels of FSGS at sympatric populations. Therefore, we also tested the hypothesis that hybrids bridge gene exchange between $E$. fulgens and E. puniceoluteum, spatially connecting both species despite their occurrence in different habitats. Our hypothesis will allow us to address the following questions: (1) Do populations of these species exhibit significant FSGS, and if yes, what are the relative roles of pollen versus seed dispersal, and biparental inbreeding or selfing rates? (2) To what extent do peripheral and core populations differ in their FSGS? (3) What can the genetic patterns tell us about the role of hybrids in connecting parental species on a spatial scale? We use our data to obtain insights into the microevolutionary patterns and processes in two closely related Neotropical orchid species. We expect higher levels of inbreeding and FSGS in the marginal populations of $E$. fulgens, and a decrease in the FSGS in hybrid zones due to the hybridization and introgression between E. fulgens and E. puniceoluteum. We highlight the need to study historical gene dispersal patterns in different species and populations with varying geographic distributions and levels of reproductive isolation, contributing to the debate on the value of peripheral populations and hybridization in species evolution.

\section{Materials and methods}

\section{Study species}

E. fulgens and E. puniceoluteum are two species inhabiting coastal sand vegetation distributed along the Brazilian Atlantic Forest and Pampas vegetation domains (Supplementary Fig. 1; Pinheiro et al. 2010; Moraes et al. 2013). The two species are clearly distinguishable based on phylogenetic, morphometric, and cytogenetic data (Pessoa et al. 2012). According to the most recent phylogenetic analysis of Epidendrum (Cardoso-Gustavson et al. 2018), E. fulgens 
and E. puniceoluteum are closely related but not sister species, belonging to the Atlantic Clade within subgenus Amphyglottium. Both species are self-compatible and pollinated by several butterfly species. Due to the absence of nectar reward in flowers from both species (Cardoso-Gustavson et al. 2018), pollinators potentially avoid plants in the same patch, decreasing the levels of inbreeding and genetic differentiation among populations (Pinheiro et al. 2010, 2011). Hybrids between these two species (Supplementary Fig. 1) were detected in several sympatric populations, with patterns of asymmetric introgression towards E. puniceoluteum (Pinheiro et al. 2010). High levels of seed sterility are observed in crosses between hybrids, but seed fertility increases when hybrids backcross with parental species (Pinheiro et al. 2010). Despite their co-occurrence, E. fulgens and E. puniceoluteum show different ecological preferences. Populations of E. fulgens occur in shrubby sand dune vegetation not subject to flooding. By contrast, $E$. puniceoluteum occurs in the interdune vegetation zone, composed of sedge swamp communities that are flooded during the rainy season (November-April), and located in depressions between successive beach ridges (Supplementary Fig. 1 and Fig. 1b). Within sympatric populations, hybrids show no preference for any particular vegetation, occurring in flooded and non-flooded sites (Pinheiro et al. 2010). While E. puniceoluteum occurs in the same vegetation throughout its geographic distribution, E. fulgens is more abundant and widespread, also occurring in rock outcrops and at comparatively higher elevations in its southern distribution (Fig. 1). For this reason, only E. fulgens was used to test for the occurrence of different FSGS patterns in peripheral versus core populations. To explore how hybridization influences the FSGS of parental species, we used allopatric and sympatric populations of E. fulgens and E. puniceoluteum.

\section{Study sites and sampling}

During the summers of 2008 and 2009, we sampled 15 sympatric and allopatric populations of E. fulgens and $E$. puniceoluteum along an 1100-km latitudinal transect from the southern range limit in Rio Grande do Sul, Brazil $\left(-30.90^{\circ} \mathrm{S}\right)$, to the northern range limit in São Paulo, Brazil ( $-44.95^{\circ}$ S; Fig. 1; see Table 1). Range limits were determined from intensive geographic surveys of site occupancy and analysis of location data from herbarium specimens collected over the last 100 years (Pinheiro et al. 2011). Sympatric and allopatric populations of E. fulgens and $E$. puniceoluteum were collected along the distribution ranges of both species (Table 1, Fig. 1). At sympatric populations, samples of both species and hybrids were collected, except for population Florianópolis, where only E. fulgens and hybrids were found. Individuals were collected randomly with a minimum sampling distance of $10 \mathrm{~m}$. Clonal plants (individuals growing with many stems close to each other) were avoided during sampling, thus allowing us to focus the present study on the effects of hybridization in the FSGS of parental species and hybrids. Samples were previously genotyped by Pinheiro et al. $(2010,2011)$ and here were used to test for the first time the effects of latitudinal gradient and hybridization on the FSGS of E. fulgens and $E$. puniceoluteum. Genetic data is based on nine nuclear simple sequence repeat loci (eff26, eff29, eff43, eff45, eff61, eff70, epp10, epp18, epp86; Pinheiro et al. 2008a, 2008b) genotyped by Pinheiro et al. (2010, 2011). We included all populations for which detailed GPS-based geographic coordinates were available for each plant (1-2 accuracy), thus facilitating FSGS analysis. Sample sizes, names, and geographical coordinates of each population sampled are given in Table 1. For each individual plant collected, fresh leaves were dried in silica gel and stored at room temperature until laboratory analysis. In total, 581 individuals from 15 populations were analyzed.

\section{Data analysis}

We analyzed the FSGS of the following groups of individuals from each sample site: (i) pure E. fulgens from all populations; (ii) pure E. puniceoluteum from all populations; (iii) sympatric E. fulgens and E. puniceoluteum; (iv) sympatric E. fulgens, E. puniceoluteum, and hybrid samples. Parental species and hybrids were classified based on genetic assignment tests using the program STRUCTURE version 2.2 (Pritchard et al. 2000), previously reported by Pinheiro et al. (2010). Assignment values for each individual used in our FSGS analysis were included in Supplementary Table 1.

For the FSGS analysis, we estimated the spatial autocorrelation using the kinship coefficient between pairs of individuals $\left(F_{i j}\right)$, using Nason's estimator, as it weighs the allele contribution and is not biased by low-frequency alleles (Loiselle et al. 1995). Average pairwise $F_{i j}$ estimates were plotted against pairwise spatial distances. Distance classes were defined with variable intervals, maximizing the number of pairs of individuals analyzed in each class. For each distance interval, the standard deviation (SD) of the average pairwise $F_{i j}$ estimates was obtained using the jackknife method with 1000 replications of loci, which was also used to calculate the $95 \%$ confidence interval of the pairwise spatial autocorrelation for the null hypothesis of no genetic structure $\left(F_{i j}=0\right)$. The overall extent of spatial genetic structure in each population was quantified by calculating $S p=-b-\log /(1-F 1)$, in which $b-\log$ is the slope of the linear regression between the pairwise kinship and the logarithm of spatial distance between pairs of individuals, and $F 1$ is the average pairwise kinship between all 
Fig. 1 Distribution map of Epidendrum fulgens and $E$. puniceoluteum based on field collection and herbarium material, and location of the populations studied. a Yellow, red, and purple circles indicate the presence of E. fulgens, E. puniceoluteum, and hybrids, respectively. Outlined circles indicate significant FSGS. b Schematic representation of a transect from the beach to inland, indicating the habitats where E. fulgens, $E$. puniceoluteum, and hybrids occur. PR Paraná, RS Rio Grande do Sul, SC Santa Catarina, SP São Paulo states (a)

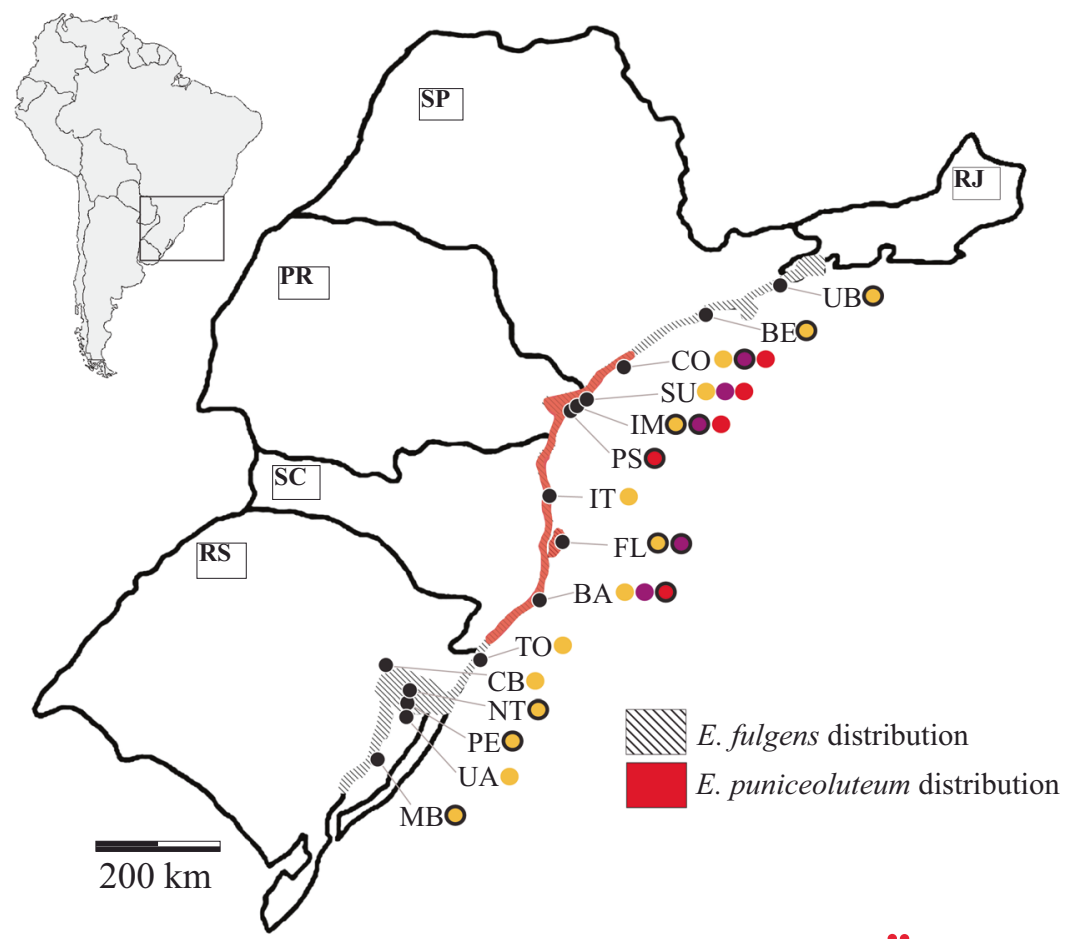

(b)
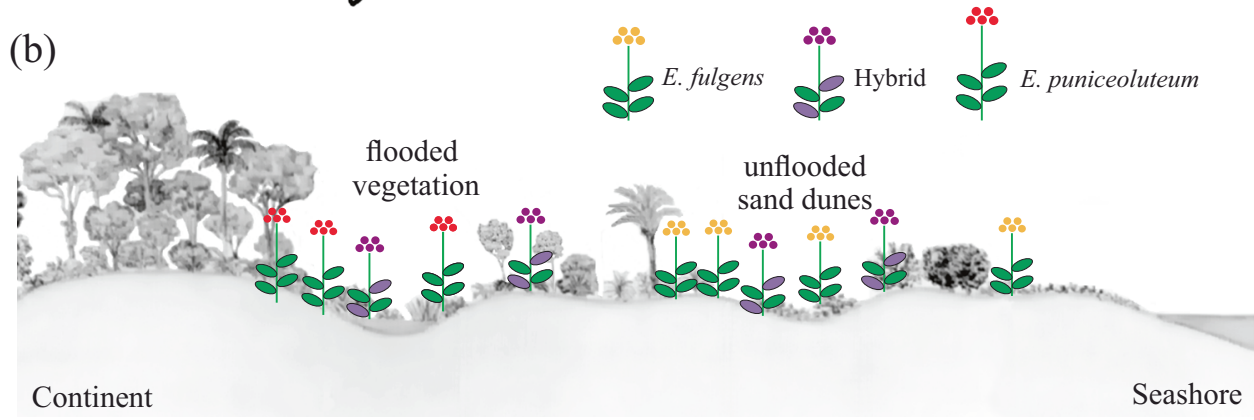

individuals in the first distance class, which includes all the neighboring pairs (Vekemans and Hardy 2004). The null hypothesis of absence of structure $(b-\log =0)$ was tested using the Mantel test and significance was obtained from 1000 bootstrap replications. All computations were carried out using the SPAGeDi 1.2 program (Hardy and Vekemans 2002).

We investigated short-distance and long-distance limitations of intrapopulation gene flow by analyzing the curvature of the FSGS plots (Heuertz et al. 2003). We obtained the residuals of a linear regression of $F_{i j}$ on the logarithm of distance and fitted it to a third-degree polynomial curve, $y$ $=a+b \ln (x)+c(\ln (x))^{2}+d(\ln (x))^{3}$. The shape of the polynomial regression indicates whether there is a shortdistance or long-distance limitation of gene dispersal. This shape is given by $k=2 c+6 d \ln (x)$. If $k$ is larger than zero (concave shape), there is an indication of restricted shortdistance gene dispersal, while negative $k$ indicates no restriction at this scale.
We calculated Wright's fixation index (Fis) as an inbreeding estimator (Weir and Cockerham 1984) using the hierfstat package (Goudet, 2005) in R (R Core Team 2015). We compared $f$ (inbreeding coefficient) with $F_{i j}$ to assess the contribution of selfing and biparental inbreeding to total inbreeding, using a one-sided non-parametric Kolmogorov-Smirnov test in R (R Core Team 2015). Significant differences indicated that inbreeding was mainly due to selfing (Barbará et al. 2008).

The hypothesis that $E$. fulgens populations at range margins show contrasting patterns of FSGS when compared to core populations was tested by assessing the regression between latitudes against $f$ and the $S p$ statistic. The relationships between latitude and genetic parameters were tested by linear, quadratic, and cubic regression models, and the most likely model was selected based on the highest percentage variance explained $\left(\mathrm{PVE}=R^{2}\right)$. Analyses were performed using the SPSS 11.0 software (SPSS, Inc., Chicago, IL, USA). 
Table 1 Allopatric (A) and sympatric (S) populations of Epidendrum fulgens, $E$. puniceoluteum, and respective hybrids sampled for this study, including sample sizes $(N)$, population codes, geographical coordinates, and habitat description

\begin{tabular}{|c|c|c|c|c|c|c|}
\hline Population & Species (sample size) & $N$ & ID & Latitude S & Longitude W & Habitat \\
\hline Ubatuba (A) & E. fulgens & 18 & UB & $23^{\circ} 22^{\prime}$ & $44^{\circ} 57^{\prime}$ & Sand dune vegetation \\
\hline Bertioga (A) & E. fulgens & 20 & $\mathrm{BE}$ & $23^{\circ} 46^{\prime}$ & $45^{\circ} 57^{\prime}$ & Sand dune vegetation \\
\hline \multirow[t]{3}{*}{ Ilha Comprida (S) } & E. fulgens & 18 & $\mathrm{CO}$ & $24^{\circ} 51^{\prime}$ & $47^{\circ} 42^{\prime}$ & Sand dune vegetation \\
\hline & E. puniceoluteum & 26 & & & & \\
\hline & Hybrids & 25 & & & & \\
\hline \multirow[t]{3}{*}{ Ilha de Superagui (S) } & E. fulgens & 18 & $\mathrm{SU}$ & $25^{\circ} 27^{\prime}$ & $48^{\circ} 13^{\prime}$ & Sand dune vegetation \\
\hline & E. puniceoluteum & 10 & & & & \\
\hline & Hybrids & 22 & & & & \\
\hline \multirow[t]{3}{*}{ Ilha do Mel (S) } & E. fulgens & 23 & $\mathrm{IM}$ & $25^{\circ} 31^{\prime}$ & $48^{\circ} 17^{\prime}$ & Sand dune vegetation \\
\hline & E. puniceoluteum & 19 & & & & \\
\hline & Hybrids & 25 & & & & \\
\hline Pontal do Sul (A) & E. puniceoluteum & 33 & PS & $25^{\circ} 39^{\prime}$ & $48^{\circ} 26^{\prime}$ & Sand dune vegetation \\
\hline Itajaí (A) & E. fulgens & 20 & IT & $26^{\circ} 56^{\prime}$ & $48^{\circ} 37^{\prime}$ & Sand dune vegetation \\
\hline \multirow[t]{2}{*}{ Florianópolis (S) } & E. fulgens & 53 & FL & $27^{\circ} 37^{\prime}$ & $48^{\circ} 27^{\prime}$ & Sand dune vegetation \\
\hline & Hybrids & 15 & & & & \\
\hline \multirow[t]{3}{*}{ Imbituba (S) } & E. fulgens & 45 & BA & $28^{\circ} 10^{\prime}$ & $48^{\circ} 41^{\prime}$ & Sand dune vegetation \\
\hline & E. puniceoluteum & 9 & & & & \\
\hline & Hybrids & 34 & & & & \\
\hline Torres (A) & E. fulgens & 25 & TO & $29^{\circ} 22^{\prime}$ & $49^{\circ} 45^{\prime}$ & Sand dune vegetation \\
\hline Morro do Cabrito (A) & E. fulgens & 22 & $\mathrm{CB}$ & $29^{\circ} 37^{\prime}$ & $51^{\circ} 39^{\prime}$ & Arenitic rock outcrop \\
\hline Morro Santana (A) & E. fulgens & 20 & NT & $30^{\circ} 03^{\prime}$ & $51^{\circ} 07^{\prime}$ & Granitic rock outcrop \\
\hline Morro São Pedro (A) & E. fulgens & 21 & PE & $30^{\circ} 11^{\prime}$ & $51^{\circ} 06^{\prime}$ & Granitic rock outcrop \\
\hline Itapuã (A) & E. fulgens & 37 & UA & $30^{\circ} 21^{\prime}$ & $51^{\circ} 02^{\prime}$ & Granitic rock outcrop \\
\hline Arambaré (A) & E. fulgens & 22 & MB & $30^{\circ} 54^{\prime}$ & $51^{\circ} 29^{\prime}$ & Sand dune vegetation \\
\hline
\end{tabular}

Populations are indicated as shown on the map in Fig. 1a

\section{Results}

Half of the populations analyzed showed significant FSGS (Table 2, Supplementary Fig. 2). For only four populations of pure E. fulgens, the kinship coefficient was significantly larger than zero in the first distance class (Supplementary Fig. 2). However, the regression of $F_{i j}$ on the logarithm of distances was significant for these four and other populations of both species and hybrids. Similar $S p$ values were obtained for E. fulgens ( -0.0002 to 0.0593 , mean: 0.014) and E. puniceoluteum ( -0.0025 to 0.0610 , mean: 0.020 ). Lower $S p$ values were observed for hybrids $(0.000-0.0149$, mean: 0.005). For combined populations of $E$. fulgens and $E$. puniceoluteum, we observed higher $F_{i j}$ than values obtained for pure species populations. $F_{i j}$ for combined populations varied from 0.0138 to 0.2450 , with values significantly different from zero for three out of four groups analyzed (Table 2, Fig. 2). We observed $S p$ values for these groups from 0.007 to 0.119 . For groups that included both species and hybrids, we observed lower $F_{i j}(0.0020-0.1286)$ and $S p$ values (0-0.053), as observed in Table 2 and Fig. 2.

Only E. fulgens populations showed $f$ estimates significantly larger than zero (Table 2 ). The estimated $f$ varied from -0.009 to 0.180 for E. fulgens populations, and from
-0.034 to 0.219 for E. puniceoluteum. Hybrid populations showed the smaller values for $f$, from -0.079 to 0.045 and the only $f$ value significantly smaller than zero. Most populations did not show significant differences between $f$ and $F_{i j}$ (Table 2). Only one population of E. fulgens showed $f<F_{i j}$, indicating the occurrence of selfing. It was possible to investigate the limitation of intrapopulation gene dispersal in four E. fulgens populations, in which $k<0$ was observed, indicating a limitation of long-distance gene flow (Table 3). For the remaining populations, FSGS was not significant or was not strong enough for robust analysis. For most populations with significant FSGS, it was not possible to fit the residuals of the linear regression of $F_{i j}$ on the logarithm of distance to a polynomial curve. Without the constants of the polynomial equation, it was not possible to calculate $k$.

The distribution of inbreeding coefficients across the range of the sampled populations of E. fulgens was not associated with latitude when considering linear $(P=$ $0.700)$, quadratic $(P=0.473)$, or cubic equations $(P=$ 0.487). By contrast, the relationship between $S p$ and latitude was best described by the cubic model $\left(R^{2}=0.512\right.$, $P<0.05)$. The model indicated higher values of FSGS at 


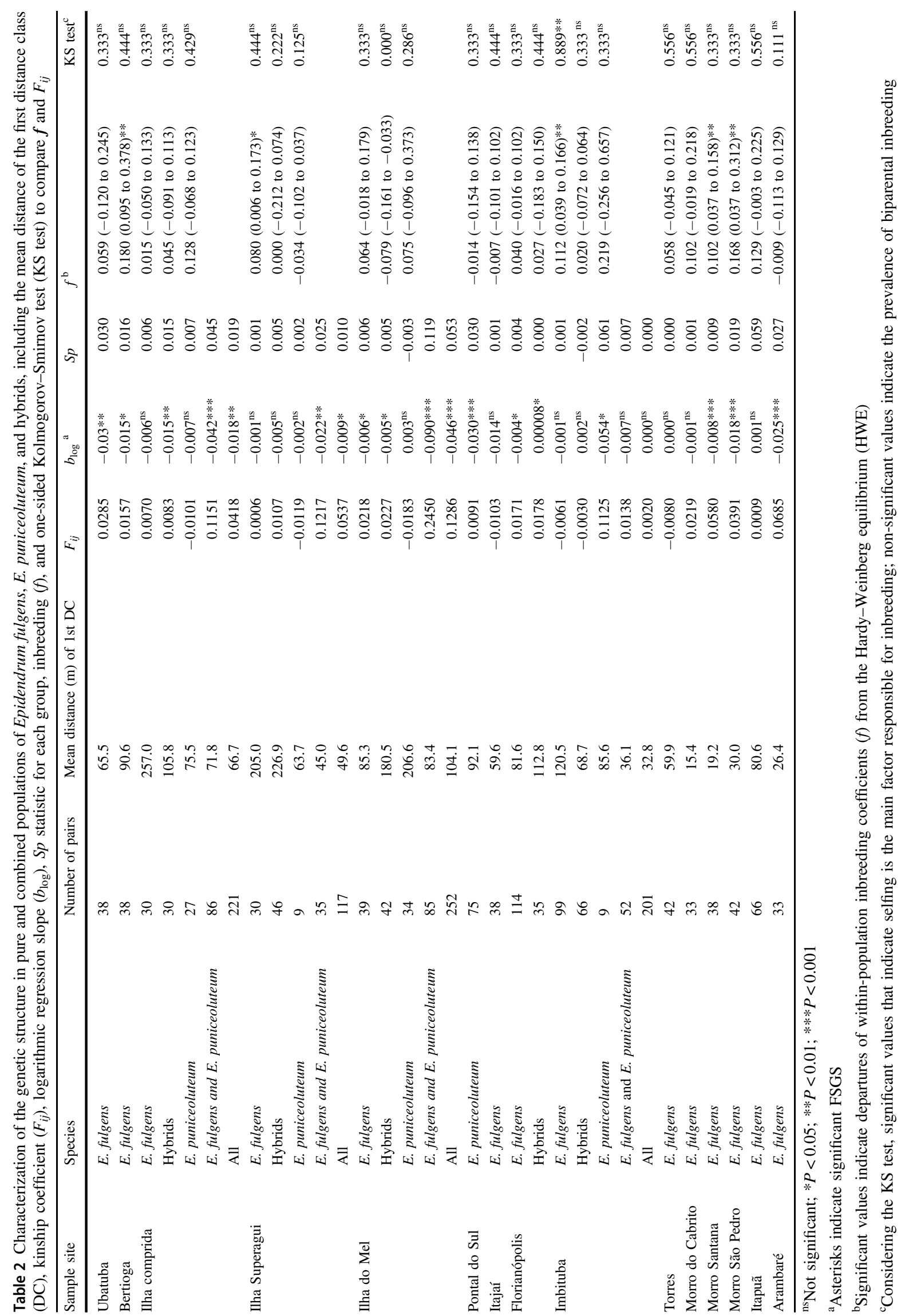


Fig. 2 Interspecific autocorrelograms of Epidendrum fulgens and $E$. puniceoluteum in four sympatric populations, considering only parental species (triangles and dotted lines) and both species jointly with hybrids (circles and solid lines)

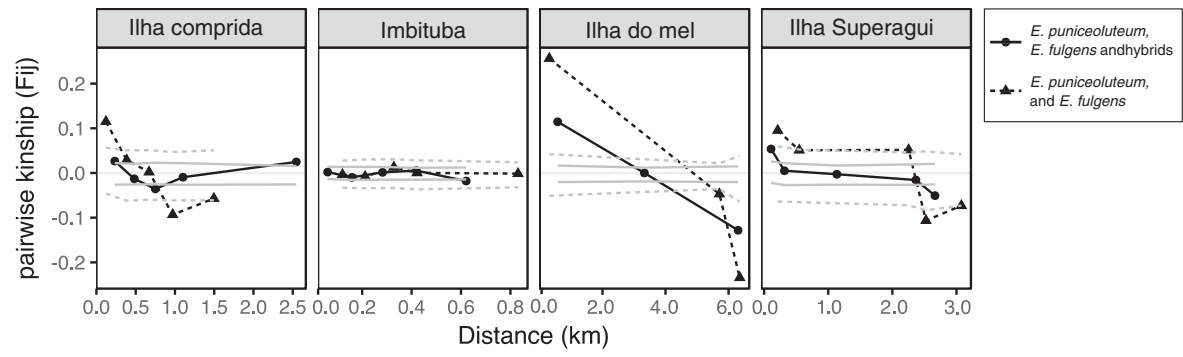

Table 3 Estimates for the limitation of intrapopulation gene flow analysis, where $k$ represents the shape of the polynomial regression, which indicates limitation of gene dispersal; $c$ and $d$ are constants of the polynomial curve used to calculate $k$

\begin{tabular}{lllll}
\hline Sample site & $\begin{array}{l}\text { Mean distance }(\mathrm{m}) \\
\text { of 1st DC }\end{array}$ & $k$ & $c$ & $d$ \\
\hline Florianópolis & 81.6 & -0.647 & -1.608 & 0.354 \\
Morro Santana & 19.2 & -1.495 & -0.544 & 0.197 \\
Morro São Pedro & 30.0 & -2.357 & -3.630 & 0.811 \\
Arambaré & 26.4 & -4.300 & -7.607 & 1.874
\end{tabular}

Negative values of $k$ indicate restrictions of gene exchange over long distances, suggesting low pollen dispersal

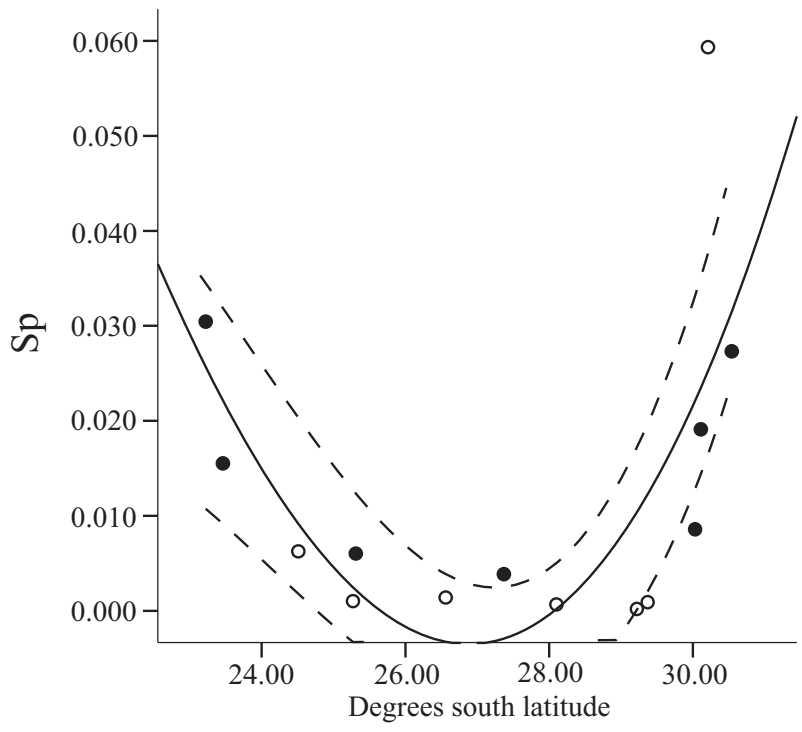

Fig. 3 Geographical trends of FSGS of Epidendrum fulgens populations in southern and south-eastern Brazil. Association between latitude and $S p$ statistic $\left(R^{2}=0.512, P<0.05\right)$ described by the cubic regression model, showing a significant increase in FSGS towards peripheral populations. Filled circles indicate populations with significant FSGS (see Table 2 for details). Dashed lines represent 95\% confidence intervals calculated based on individual predicted $y$ values from the regression line (as indicated in SPSS v.11.0)

peripheral populations, with a tendency to decrease in central populations (Fig. 3).

\section{Discussion}

By studying within-population FSGS in two coastal orchid species with distinct ecological preferences, we aimed to improve our understanding of the complex interactions between geography, hybridization, and introgression at local scales. Significant FSGS was found in nearly half of the populations of both species, indicating limited pollen and seed dispersal within populations. Inbreeding levels were very low for most populations, in agreement with the patterns expected for species pollinated by food deception (Scopece et al. 2010). When significant values were found, biparental inbreeding instead of selfing was identified as the main force shaping the kinship within populations. We detected a significant increase in FSGS towards peripheral populations, a pattern observed when adults are less abundant and offspring establishment predominantly occurs near maternal plants (Gapare and Aitken 2005; Chung et al. 2007). At sympatric sites where E. fulgens and E. puniceoluteum hybridize, the levels of FSGS of both parental species decrease when hybrids are analyzed together, suggesting that introgression shapes the FSGS of hybridizing species at local spatial scales. Our study suggests that both geographic distribution and hybridization are key components shaping the ecology and evolution of species ranges.

\section{Ecological traits and FSGS in Epidendrum}

The observed mean $S p$ statistics for populations of $E$. fulgens (0.014) and E. puniceoluteum (0.020) are within the range for species with a predominantly outcrossing breeding system (range: 0.0020-0.0393, Vekemans and Hardy 2004). Significant FSGS was detected in seven out of 14 populations of $E$. fulgens and in two out of five populations of E. puniceoluteum, suggesting that seed and pollen dispersal within populations are restricted to different degrees along the distribution range of both species (Table 2). In fact, as the species studied here were represented by several populations, our data can be interpreted in terms of variation in pollen and seed dispersal among populations in these coastal plant species. Significant FSGS structure followed by significant inbreeding was detected for only three populations of E. fulgens (Tables 2 and 3), and biparental 
inbreeding instead of selfing was the main force shaping the restriction of gene exchange in these orchid populations (Table 2). Thus, significant FSGS followed by inbreeding is absent in most populations, suggesting higher levels of pollen dispersal compared to seeds (Barbará et al. 2008; Opedal et al. 2017).

Broad pollen dispersal is one of the most conspicuous traits of food-deceptive orchids, since pollinators avoid visiting plants in the same patch, resulting in pollen dispersal over long distances (Scopece et al. 2010). To date, high levels of gene exchange by pollen and low genetic differentiation have been found among populations of $E$. fulgens (Pinheiro et al. 2011) and E. puniceoluteum (Pinheiro et al. 2010). When significant FSGS is not followed by high inbreeding levels, restrictions in seed dispersal may increase the kinship of individuals over small distances. Most studies using orchids as models have detected significant FSGS due to restricted seed dispersal, in agreement with our results (Jacquemyn et al. 2006; Torres et al. 2019). Seed dispersal over long distances has been hypothesized for orchids (Tremblay et al. 2005) but not confirmed by empirical FSGS data. Only occasional long-distance dispersal events by seeds have been detected (Cozzolino et al. 2003). A detailed inspection of the significant FSGS values revealed that most cases were found in southern populations of E. puniceoluteum, and were more frequent in marginal populations of E. fulgens (Fig. 1, Table 2). Differences in population densities resulting from habitat disturbance, patchy occupancy, and specific cases of low pollen dispersal may account for the increase in FSGS in marginal populations, and this topic is discussed below.

\section{Different patterns of FSGS in central versus marginal populations}

Despite the low levels of FSGS found for both Epidendrum species, values of $S p$ statistics were variable among populations (Table 2). In fact, a significant latitudinal gradient of $S p$ values was found for the more widespread and abundant species, E. fulgens. Higher and significant levels of FSGS were found in marginal populations, when compared to the central distribution of the species range (Figs. 1 and 3, Table 2). The lack of spatial genetic structure in core populations is a logical outcome predicted by the central-marginal hypothesis, which also predicts lower population densities and higher inbreeding at peripheral populations (Eckert et al. 2008). Core populations usually have higher densities with a more continuous distribution of adult plants than peripheral populations, leading to overlapping seed shadows that would limit the development of genetic structure (Hamrick and Trapnell 2011). Vekemans and Hardy (2004) reviewed patterns of FSGS among plant populations differing in adult density, and detected a significant increase in FSGS in populations with lower densities. Other predictions such as the decrease in genetic diversity and occurrence of bottlenecks at marginal populations were also previously confirmed for $E$. fulgens (Pinheiro et al. 2011). Historical and contemporary processes may shape the increase of FSGS towards peripheral populations (Eckert et al. 2008). More importantly, different ecological and evolutionary processes may affect dispersal and densities at northern and southern range limits (Samis and Eckert 2007, 2009).

Historical range contraction and expansion of tropical forests and the current demographic dynamics of sand dune vegetation communities may contribute to the increase in FSGS of northern E. fulgens populations. Sand dune vegetation among northern populations of $E$. fulgens (Ubatuba and Bertioga) is currently constrained by the advance of the Brazilian Atlantic Forest after the Last Glacial Maximum (Behling 2002). This pattern gradually changes towards the south, where sand dune vegetation becomes wider $(1-10 \mathrm{~km})$ and more connected (Seeliger 1992). Quaternary sand dunes are found in the central and southern ranges of the E. fulgens distribution, and potentially acted as refugia for coastal vegetation communities during climatic oscillation events (Pinheiro et al. 2011, 2015). In addition, current ecological dynamics found in coastal vegetation habitats, such as storms and dune movement, may increase disturbance and species turnover in coastal plant communities (Crawford 2008; Gornish and Miller 2010). This type of habitat disturbance would be intensified in narrow sand dune plant communities found at the northern range of E. fulgens (Pinheiro et al. 2011). Dispersal limitations, as observed in marginal $E$. fulgens populations, may destabilize population dynamics at range limits due to a reduction in patchy occupancy after extinction events (Holt et al. 2005). Previous results have shown an increase in FSGS in populations occurring in variable environments (Mosca et al. 2018). According to Chung et al. (2007), a combination of low genetic diversity and non-significant FSGS, as observed in northern E. fulgens populations, may indicate demographic decline. In contrast, according to the same authors, low genetic diversity but significant FSGS are signs of population expansion, as observed in southern E. fulgens populations. Indeed, phylogeographic studies have tracked shrinkage of northern populations and expansion of southern populations for species distributed in similar geographic ranges (Cardoso et al. 2015; Ramos-Fregonezi et al. 2015; Silva-Arias et al. 2017).

The restrictions of habitat size and availability observed for northern populations of $E$. fulgens are not observed at southern range limits. Sand dune plant communities are much wider and extend several kilometers inland (Seeliger 1992). Contrary to the patterns observed for most 
populations, restrictions of pollen dispersal were confirmed in three E. fulgens populations at the southern range limit (Fig. 1a, Table 3), suggesting pollen exchange among neighbor plants. A number of ecological processes may explain restrictions of pollen dispersal in different plant populations, such as degree of habitat fragmentation (Opedal et al. 2017), changes in the fauna of pollinators, or changes in pollinators' behavior (see review by Barrett 2010; Wright et al. 2013). Several factors may thus act simultaneously to shape higher levels of FSGS in southern populations of E. fulgens. A change in butterfly behavior at southern populations of $E$. fulgens seems less probable because pollinator flight distances tend to increase at sites with lower plant densities (e.g., Levin and Kerster 1969; Fenster 1991). Studies have shown that different pollinator species visit E. fulgens at the Torres (Fuhro et al. 2010) and Ubatuba populations (Pansarin and Amaral 2008); distinct species showing shorter flight distances may thus occur at southern populations. Local pollinator assemblages may change patterns of FSGS across different plant populations (Meeus et al. 2013). Despite the restrictions of pollen dispersal, significant biparental inbreeding was detected for populations at Morro Santana and Morro São Pedro (Table 2), suggesting that pollination by deceit is an efficient strategy in avoiding self-pollination, even when plants occur at low densities. Future studies aiming to identify E. fulgens pollinators, mainly at southern populations, may clarify the spatial limits of pollen dispersal and differences in pollinator compositions, when compared to northern sites.

\section{Hybridization links spatially and ecologically segregated species}

The sympatric sites analyzed here are distributed in the central distribution range of $E$. fulgens, where the ecological and evolutionary forces shaping range margins are not expected to occur (Fig. 1a). In hybrid zones, E. fulgens and E. puniceoluteum occur in different but adjacent habitats, and hybrids are found intermingled with both parental species (Fig. 1b). The occurrence of introgression at different hybrid zones (Pinheiro et al. 2010) suggests that gene flow between parental species occurs, but the spatial impact of the interspecific gene exchange was never tested. Indeed, few studies have investigated hybrid zones using an FSGS approach (Cornman et al. 2004; Valbuena-Carabanã et al. 2007; Van Loo et al. 2008, Field et al. 2011). The role of clonality in the persistence of hybrids in time and space, and higher levels of FSGS in hybrids than in parental taxa, suggesting interspecific gene exchange and assortative mating, were found for poplar species (Van Loo et al. 2008). In contrast, hybrid persistence in an iris hybrid zone was due to sexual reproduction, also showing very low levels of inbreeding (Cornman et al. 2004). Using oak species as models, Valbuena-Carabanã et al. (2007) showed hybrids acting as bridges for gene exchange between parental taxa, decreasing the levels of FSGS observed in hybrid zones. Similar patterns were found for three out of four replicate hybrid zones between E. fulgens and E. puniceoluteum (Fig. 2). Hybrids consistently decrease the levels of total FSGS observed in sympatric populations, suggesting that interspecific gene exchange dilutes the spatial segregation between $E$. fulgens and E. puniceoluteum. Our results are in agreement with the findings of ValbuenaCarabanã et al. (2007), suggesting that interspecific gene exchange may impact the spatial structure of populations. Hybridization may reduce FSGS through lowering kinship among parental species, because hybrids do not show specific preferences for different habitats (Fig. 1). At short distances, hybridization and introgression would result in spatial clustering of individuals bearing alleles from different species (Valbuena-Carabanã et al. 2007). More importantly, similar patterns were observed in oak (Valbuena-Carabanã et al. 2007) and orchid species (this study), suggesting that hybrids may change the FSGS of hybrid zones regardless of the life-history traits of parental taxa (short vs. long generation time, wind vs. animal pollen dispersal, wind vs. animal seed dispersal, etc.). Thus, a comparative analysis of hybrids and parental species is of particular relevance to our understanding of the evolution of hybrid zones in a local spatial context.

The observed $S p(0.005)$ in the hybrids was 2.8 and 4.0 times lower than that for E. fulgens and E. puniceoluteum, respectively (Table 2), indicating dispersal of pollen and seeds over longer distances when compared to parental species. In addition, low levels of inbreeding were found (mean $f=0.003$ ), suggesting that selfing is almost absent among hybrid plants. Indeed, pollen sterility is very strong in hybrids between E. fulgens and E. puniceoluteum, and viable seeds are formed only when hybrids act as pollen receptors from parental species (Pinheiro et al. 2010). We draw two general conclusions from these results: (1) recombination among hybrids and parental species has occurred over large spatial distances because hybrid plants are less ecologically constrained, and (2) hybrid persistence relies mainly on sexual reproduction involving parental species producing $\mathrm{F} 1$ and backcrossed hybrids.

The consequences of hybridization between distinct lineages can result in a variety of outcomes (reviewed by Vallejo-Marín and Hiscock 2016; Goulet et al. 2017); here we explore two potential evolutionary pathways. Hybrids may become a new species when they colonize niches unavailable to parents, decreasing competition and increasing levels of reproductive isolation (Mallet 2007). In such cases, clonal reproduction, inbreeding, and assortative mating (Cornman et al. 2004; Van Loo et al. 2008; Field 
et al. 2011) are mechanisms that increase hybrid persistence and may contribute to complete speciation. This possibility seems unlikely here, because in this case, hybrid persistence is still dependent on the parental species, with no evidence of clonal propagation or occurrence in an alternative habitat (Pinheiro et al. 2010). However, hybrid persistence may favor interspecific gene exchange, moving adaptive variation between parental species (Anderson and Stebbins 1954; Vekemans 2010; Cannon and Lerdau 2015). Adaptive gene introgression can modify several traits of the recipient species, increasing adaptation to both abiotic and biotic features of the environment (Vekemans 2010). The exchange of adaptive alleles may decrease the risk of extinction in populations occurring at low frequencies or in often-disturbed environments by increasing their diversity and adaptive potential (Cannon and Lerdau 2015). This scenario may apply for the hybrid zones studied here, where introgression expands the spatial frontiers of alleles from $E$. fulgens and E. puniceoluteum. In this case, introgression would increase dispersal and resilience of both species, and decrease their extinction risks in harsh coastal vegetation communities, which are prone to several natural and human-induced disturbances (Scarano et al. 2002). Indeed, high levels of gene exchange between populations and species occurring in different microhabitats have been documented in coastal plant communities (Silva-Arias et al. 2017; Meireles and Manos 2018). This hypothesis deserves future testing using genomic tools to demonstrate that alleles contributing to an adaptive phenotype in recipient species are in fact introgressed, as well as ecological experiments to identify whether modified traits are associated with adaptation to environmental pressures such as drought and salinity (Hoban et al. 2016). Such experiments would provide important information regarding the role of hybrid zones in the origin and maintenance of the high levels of biological diversity observed in tropical regions.

\section{Conclusions and future prospects}

This study provides a compelling argument for the importance of pollen and seed dispersal in shaping the FSGS among central versus marginal populations and within hybrid zones. In our study system, significantly higher levels of FSGS were found at peripheral populations when compared to the core distribution of the species range, supporting the perspective that seed and pollen dispersal change across species distribution ranges (Bridle and Vines 2007; Eckert et al. 2008). Differences in pollen movement, habitat availability, and inbreeding were found in northern and southern peripheral populations, suggesting distinct ecological and evolutionary forces acting at both marginal ranges, in agreement with previous studies using coastal species as models (Samis and Eckert 2007). An opposite pattern was observed in the core distribution of E. fulgens, where E. puniceoluteum co-occurs in sympatry. Hybridization decreased the total FSGS in three out of four hybrid zones, expanding the spatial limits of interspecific allele recombination. In this context, hybrids act as bridges for gene exchange between parental taxa, which may benefit from the transfer of potential adaptive alleles. Given the frequent natural and human-induced disturbances occurring in coastal plant communities, the introgression of adaptive alleles may decrease extinction risks of populations (Cannon and Lerdau 2015), increasing the diversity and ecological resilience commonly found in these harsh communities (Scarano 2002). Further analysis combining specific genomic tools, such as Rad-seq and transcriptome sequencing will allow identification of genome signatures of selection and differential gene expression in populations distributed in core versus peripheral populations, as well the identification of specific introgressed alleles in recipient species. Integrated ecological experiments such as reciprocal transplants, reproductive biology experiments, and the analysis of traits associated with dispersal potential will cross-validate the mechanisms unveiled using genomic tools. This multidisciplinary approach will facilitate tests of the hypothesis raised by literature reviews (Bridle and Vines 2007; Hargreaves and Eckert 2014), as well as that identified here: (a) that southern and northern range margins are influenced by different biotic and abiotic pressures and (b) that introgressed alleles may have an adaptive value, increasing the resilience and ecological plasticity of hybridizing species. In closing, we suggest that future studies would benefit from including different species and populations, occurring at sympatric and allopatric sites, when attempting to characterize which ecological and evolutionary forces are shaping the patterns of FSGS.

\section{Data archiving}

The data sets used for this study, including the SSR genotypes for E. fulgens, E. puniceoluteum, and hybrids, are available from the Dryad Digital Repository: https://doi.org/ 10.5061/dryad.421dq43.

Acknowledgements We thank V. Tranchida-Lombardo and R. Rinaldi for helping in the laboratory. Funding for this study was provided by grants from the Conselho Nacional de Desenvolvimento Científico e Tecnológico (CNPq-300927/2016-9) and Fundação de Amparo à Pesquisa do Estado de São Paulo (FAPESP-2006/54189-3, 2009/15052-0, 2019/04918-9) to F.P. F.P received fellowship from CNPq and CAPES.

Author contributions F.P. collected samples in the field. F.P. collected the molecular data. P.S.S. realized statistical analyses with the contributions from F.P. F.P., P.S.S., and S.C. wrote the manuscript. All authors read, edited, and approved the final manuscript. 


\section{Compliance with ethical standards}

Conflict of interest The authors declare that they have no conflict of interest.

Publisher's note: Springer Nature remains neutral with regard to jurisdictional claims in published maps and institutional affiliations.

\section{References}

Anderson E, Stebbins GL (1954) Hybridization as an evolutionary stimulus. Evolution 8:378-388

Barbará T, Lexer C, Martinelli G, Mayo S, Fay MF, Heuertz M (2008) Within-population spatial genetic structure in four naturally fragmented species of a neotropical inselberg radiation, Alcantarea imperialis, A. geniculata, A. glaziouana and A. regina (Bromeliaceae). Heredity 101:285-296

Barrett SCH (2010) Understanding plant reproductive diversity. Philos Trans R Soc Lond B Biol Sci 365:99-109

Behling H (2002) South and southeast Brazilian grasslands during Late Quaternary times: a synthesis. Palaeogeogr Palaeoclim Palaeoecol 177:19-27

Berens DG, Braun C, González-Martínez SC, Griebeler EM, Nathan R, Böhning-Gaese K (2014) Fine-scale spatial genetic dynamics over the life cycle of the tropical tree Prunus africana. Heredity 113:401-407

Binks RM, Millar MA, Byrne M (2015) Contrasting patterns of clonality and fine-scale genetic structure in two rare sedges with differing geographic distributions. Heredity 115:235-242

Bridle JR, Vines TH (2007) Limits to evolution at range margins: when and why does adaptation fail? Trends Ecol Evol 22:140-147

Cannon CH, Lerdau M (2015) Variable mating behaviors and the maintenance of tropical biodiversity. Front Genet 6:183

Cardoso DC, Cristiano MP, Tavares MG, Schubart CD, Heinze J (2015) Phylogeography of the sand dune ant Mycetophylax simplex along the Brazilian Atlantic Forest coast: remarkably low mtDNA diversity and shallow population structure. BMC Evol Biol 15:106

Cardoso-Gustavson P, Saka MN, Pessoa EM, Palma-Silva C, Pinheiro $F$ (2018) Unidirectional transitions in nectar gain and loss suggest food deception is a stable evolutionary strategy in Epidendrum (Orchidaceae): insights from anatomical and molecular evidence. BMC Plant Biol 18:179

Chung MY, Nason JD, Chung MG (2007) Effects of population succession on demographic and genetic processes: predictions and tests in the daylily Hemerocallis thunbergii (Liliaceae). Mol Ecol 16:2816-2829

Cornman RS, Burke JM, Wesselingh RA, Arnold ML (2004) Contrasting genetic structure of adults and progeny in a Louisiana Iris hybrid population. Evolution 58:2669-2681

Cozzolino S, Cofasso D, Pellegrino G, Masachhio A, Widmer A (2003) Fine-scale phylogeographical analysis of Mediterranean Anacamptis palustris (Orchidaeae) populations based on chloroplast minisatellite and microsatellite variation. Mol Ecol 12:2783-2792

Crawford RM (2008) Plants at the margin: ecological limits and climate change.Cambridge University Press, Cambridge, UK

Darling E, Samis KE, Eckert CG (2008) Increased seed dispersal potential towards geographic range limits in a Pacific coast dune plant. New Phytol 178:424-435

Eckert CG, Samis KE, Lougheed SC (2008) Genetic variation across species' geographical ranges: the central-marginal hypothesis and beyond. Mol Ecol 17:1170-1188
Fenster CB (1991) Gene flow in Chamaecrista fasciculata (Leguminosae) I. Gene dispersal. Evolution 45:398-409

Field DL, Ayre DJ, Whelan RJ, Young AG (2011) Patterns of hybridization and asymmetrical gene flow in hybrid zones of the rare Eucalyptus aggregata and common E. rubida. Heredity 106:841-853

Fuhro D, Araújo AMD, Irgang BE (2010) Are there evidences of a complex mimicry system among Asclepias curassavica (Apocynaceae) Epidendrum fulgens (Orchidaceae), and Lantana camara (Verbenaceae) in Southern Brazil?. Rev Bras Bot 33:589-598

Gapare WJ, Aitken SN (2005) Strong spatial genetic structure in peripheral but not core populations of Sitka spruce Picea sitchensis (Bong.) Carr. Mol Ecol 14:2659-2667

Gornish ES, Miller TE (2010) Effects of storm frequency on dune vegetation. Glob Chang Biol 16:2668-2675

Goudet J (2005) Hierfstat, a package for R to compute and test variance components and $F$-statistics. Mol Ecol Notes 5:184-186

Goulet BE, Roda F, Hopkins R (2017) Hybridization in plants: old ideas, new techniques. Plant Physiol 173:65-78

Guo Q (2012) Incorporating latitudinal and central-marginal trends in assessing genetic variation across species ranges. Mol Ecol 21:5396-5403

Hamrick JL, Trapnell DW (2011) Using population genetic analyses to understand seed dispersal patterns. Acta Oecol 37:641-649

Hardy OJ, Vekemans X (2002) SPAGeDi: a versatile computer program to analyse spatial genetic structure at the individual or population levels. Mol Ecol Notes 2:618-620

Hargreaves AL, Eckert CG (2014) Evolution of dispersal and mating systems along geographic gradients: implications for shifting ranges. Funct Ecol 28:5-21

Herlihy CR, Eckert CG (2005) Evolution of self-fertilization at geographical range margins? A comparison of demographic, floral, and mating system variables in central vs. peripheral populations of Aquilegia canadensis (Ranunculaceae). Am J Bot 92:744-751

Heuertz M, Vekemans X, Hausman JF, Palada M, Hardy OJ (2003) Estimating seed vs. pollen dispersal from spatial genetic structure in the common ash. Mol Ecol 12:2483-2495

Hoban S, Kelley JL, Lotterhos KE, Antolin MF, Bradburd G, Lowry DB, Whitlock MC (2016) Finding the genomic basis of local adaptation: pitfalls, practical solutions, and future directions. Am Nat 188:379-397

Holt RD, Keitt TH, Lewis MA, Maurer BA, Taper ML (2005) Theoretical models of species' borders: single species approaches. Oikos 108:18-27

Jacquemyn H, Brys R, Vandepitte K, Honnay O, Roldán-Ruiz I (2006) Fine-scale genetic structure of life history stages in the fooddeceptive orchid Orchis purpurea. Mol Ecol 15:2801-2808

Kay KM, Woolhouse S, Smith BA, Pope NS, Rajakaruna N (2018) Sympatric serpentine endemic Monardella (Lamiaceae) species maintain habitat differences despite hybridization. Mol Ecol 27:2302-2316

Levin DA, Kerster HW (1969) Dependence of bee-mediated pollen and gene dispersal upon plant density. Evolution 23:560-571

Lewontin RC, Birch LC (1966) Hybridization as a source of variation for adaptation to new environments. Evolution 20:315-336

Loiselle BA, Sork VL, Nason JD, Graham C (1995) Spatial genetic structure of a tropical understory shrub. Am J Bot 82:1420-1425

Mallet J (2007) Hybrid speciation. Nature 446:279

Meeus S, Honnay O, Jacquemyn H (2013) Differences in fine-scale spatial genetic structure across the distribution range of the distylous forest herb Pulmonaria officinalis (Boraginaceae). BMC Genet 14:101

Meireles JE, Manos PS (2018) Pervasive migration across rainforest and sandy coastal plain Aechmea nudicaulis (Bromeliaceae) 
populations despite contrasting environmental conditions. Mol Ecol 27:1261-1272

Moraes AP, Chinaglia M, Palma-Silva C, Pinheiro F (2013) Interploidy hybridization in sympatric zones: the formation of Epidendrum fulgens $\times$ E. puniceoluteum hybrids (Epidendroideae, Orchidaceae). Ecol Evol 3:3824-3837

Mosca E, Di Pierro EA, Budde KB, Neale DB, González-Martínez SC (2018) Environmental effects on fine-scale spatial genetic structure in four Alpine keystone forest tree species. Mol Ecol 27:647-658

Opedal ØH, Falahati-Anbaran M, Albertsen E, Armbruster WS, PérezBarrales R, Stenøien HK, Pélabon C (2017) Euglossine bees mediate only limited long-distance gene flow in a tropical vine. New Phytol 213:1898-1908

Pandey M, Rajora OP (2012) Higher fine-scale genetic structure in peripheral than in core populations of a long-lived and mixedmating conifer-eastern white cedar (Thuja occidentalis L.). BMC Evol Biol 12:48

Pansarin ER, Amaral MCE (2008) Reproductive biology and pollination mechanisms of Epidendrum secundum (Orchidaceae)floral variation: a consequence of natural hybridization? Plant Biol 10:211-219

Pessoa EM, Alves M, Alves-Araújo A, Palma-Silva C, Pinheiro F (2012) Integrating different tools to disentangle species complexes: a case study in Epidendrum (Orchidaceae) Taxon 61:721-734

Petit RJ, Duminil J, Fineschi S, Hampe A, Salvini D, Vendramin GG (2005) Comparative organization of chloroplast, mitochondrial and nuclear diversity in plant populations. Mol Ecol 14:689-701

Pfennig KS, Kelly AL, Pierce AA (2016) Hybridization as a facilitator of species range expansion. Proc R Soc Lond B Biol Sci 283:20161329

Pinheiro F, de Barros F, Palma-Silva C, Meyer D, Fay MF, Suzuki RM, Lexer C, Cozzolino S (2010) Hybridization and introgression across different ploidy levels in the Neotropical orchids Epidendrum fulgens and E. puniceoluteum (Orchidaceae). Mol Ecol 19:3981-3994

Pinheiro F, de Barros F, Palma-Silva C, Fay MF, Lexer C, Cozzolino S (2011) Phylogeography and genetic differentiation along the distributional range of the orchid Epidendrum fulgens: a Neotropical coastal species not restricted to glacial refugia. J Biogeogr 38:1923-1935

Pinheiro F, Cardoso-Gustavson P, Suzuki RM, Abrao MCR, Guimaraes LR, Draper D, Moraes AP (2015) Strong postzygotic isolation prevents introgression between two hybridizing Neotropical orchids, Epidendrum denticulatum and E. fulgens. Evol Ecol 29:229-248

Pinheiro F, Santos MO, Barros F, Meyer D, Salatino A, Souza AP, Cozzolino S (2008a) Isolation and characterization of microsatellite loci in the Brazilian orchid Epidendrum fulgens. Conserv Genet 9:1661-1663

Pinheiro F, Santos MO, Palma-Silva C, Barros F, Meyer D, Salatino A, Cozzolino S (2008b) Isolation and characterization of microsatellite loci in Epidendrum puniceoluteum, an endemic orchid from the Atlantic Rainforest. Mol Ecol Resour 8:1114-1116

Pritchard JK, Stephens M, Donnelly P (2000) Inference of population structure using multilocus genotype data. Genetics 155:945-959

R Core Team (2015) R: A Language and Environment for Statistical Computing Available from: https://www.R-project.org/

Ramos-Fregonezi AM, Fregonezi JN, Cybis GB, Fagundes NJ, Bonatto SL, Freitas LB (2015) Were sea level changes during the
Pleistocene in the South Atlantic Coastal Plain a driver of speciation in Petunia (Solanaceae)? BMC Evol Biol 15:92

Sagarin RD, Gaines SD (2002) The 'abundant center' distribution: to what extent is it a biogeographical rule? Ecol Lett 5:137-147

Samis KE, Eckert CG (2007) Testing the abundant center model using range-wide demographic surveys of two coastal dune plants. Ecology 88:1747-1758

Samis KE, Eckert CG (2009) Ecological correlates of fitness across the northern geographic range limit of a Pacific Coast dune plant. Ecology 90:3051-3061

Scarano FR (2002) Structure, function and floristic relationships of plant communities in stressful habitats marginal to the Brazilian Atlantic Rainforest. Ann Bot 90:517-524

Scopece G, Cozzolino S, Johnson SD, Schiestl FP (2010) Pollination efficiency and the evolution of specialized deceptive pollination systems. Am Nat 175:98-105

Seeliger U (1992) Coastal foredunes of southern Brazil: physiography, habitats, and vegetation. In: Seeliger U (ed) Coastal plant communities of Latin America. Academic Press, San Diego, CA, p. 367-381

Silva-Arias GA, Reck-Kortmann M, Carstens BC, Hasenack H, Bonatto SL, Freitas LB (2017) From inland to the coast: Spatial and environmental signatures on the genetic diversity in the colonization of the South Atlantic Coastal Plain. Perspect Plant Ecol Evol Syst 28:47-57

Torres E, Riofrío ML, Iriondo JM (2019) Complex fine-scale spatial genetic structure in Epidendrum rhopalostele: an epiphytic orchid. Heredity 122:458-467

Torroba-Balmori P, Budde KB, Heer K, González-Martínez SC, Olsson S, Scotti-Saintagne C, Casalis M, Sonké B, Dick CW, Heuertz M (2017) Altitudinal gradients, biogeographic history and microhabitat adaptation affect fine-scale spatial genetic structure in African and Neotropical populations of an ancient tropical tree species. PLoS One 12:e0182515

Tremblay RL, Ackerman JD, Zimmerman JK, Calvo RN (2005) Variation in sexual reproduction in orchids and its evolutionary consequences: a spasmodic journey to diversification. Biol J Linn Soc 84:1-54

Valbuena-Carabaña M, González-Martínez SC, Hardy OJ, Gil L (2007) Fine-scale spatial genetic structure in mixed oak stands with different levels of hybridization. Mol Ecol 16:1207-1219

Vallejo-Marín M, Hiscock SJ (2016) Hybridization and hybrid speciation under global change. New Phytol 211:1170-1187

Van Loo M, Joseph JA, Heinze B, Fay MF, Lexer C (2008) Clonality and spatial genetic structure in Populus $\times$ canescens and its sympatric backcross parent $P$. alba in a Central European hybrid zone. New Phytol 177:506-516

Vekemans X (2010) What's good for you may be good for me: evidence for adaptive introgression of multiple traits in wild sunflower. New Phytol 187:6-9

Vekemans X, Hardy OJ (2004) New insights from fine-scale spatial genetic structure analyses in plant populations. Mol Ecol 13:921-935

Volis S, Zaretsky M, Shulgina I (2010) Fine-scale spatial genetic structure in a predominantly selfing plant: role of seed and pollen dispersal. Heredity 105:384-393

Weir BS, Cockerham CC (1984) Estimating $F$-statistics for the analysis of population structure. Evolution 38:1358-1370

Wright SI, Kalisz S, Slotte T (2013) Evolutionary consequences of self-fertilization in plants. Philos Trans R Soc Lond B Biol Sci 280:20130133 